\title{
Social credit: a comprehensive literature review
}

\author{
Lean $\mathrm{Yu}^{{ }^{1 *}}$, Xinxie Li ${ }^{1}$, Ling Tang ${ }^{1}$, Zongyi Zhang ${ }^{2}$ and Gang Kou ${ }^{2}$
}

\footnotetext{
* Correspondence: yulean@amss.ac.cn ${ }^{1}$ School of Economics and Management, Beijing University of Chemical Technology, Beijing 100029, China

Full list of author information is available at the end of the article
}

\begin{abstract}
To avoid credit fraud, social credit within an economic system has become an increasingly important criterion for the evaluation of economic agent activity and guaranteeing the development of a market economy with minimal supervision costs. This paper provides a comprehensive review of the social credit literature from the perspectives of theoretical foundation, scoring methods, and regulatory mechanisms. The study considers the credit of various economic agents within the social credit system such as countries (or governments), corporations, and individuals and their credit variations in online markets (i.e., network credit). A historical review of the theoretical (or model) development of economic agents is presented together with significant works and future research directions. Some interesting conclusions are summarized from the literature review. (1) Credit theory studies can be categorized into traditional and emerging schools both focusing on the economic explanation of social credit in conjunction with creation and evolution mechanisms. (2) The most popular credit scoring methods include expert systems, econometric models, artificial intelligence (Al) techniques, and their hybrid forms. Evaluation indexes should vary across different target agents. (3) The most pressing task for regulatory mechanisms that supervise social credit to avoid credit fraud is the establishment of shared credit databases with consistent data standards.

Keywords: Social credit; Literature review; Credit scoring; Regulatory mechanism; Credit risk
\end{abstract}

\section{Introduction}

Increasing credit fraud has become the predominant problem disturbing normal economic market activities (Longstaff et al. 2005; Prati et al. 2012). The most famous cases of credit fraud are the US subprime mortgage crisis and the European sovereign debt crisis that caused substantial damage to global economic systems. Such devastating effects increase the need for the study of social credit to evaluate credit risk (i.e., credit rating or credit scoring) and to avoid further credit fraud. Credit fraud has become a predominant subject of focus for academic researchers and practitioners within the fields of economic and financial management. Therefore, this paper particularly focuses on social credit analysis and provides a comprehensive literature review with an insightful perspective on social credit and methods to avoid possible credit fraud at the global level.

Credit fraud problems stem from information asymmetries among economic agents (Petersen and Rajan 2002); therefore, social credit evaluates the economic activities of various economic agents such as countries (or governments), corporations, and individuals and their credit variations in online markets (i.e., network credit).

(c) 2015 Yu et al.; licensee Springer. This is an Open Access article distributed under the terms of the Creative Commons Attribution License (http://creativecommons.org/licenses/by/4.0), which permits unrestricted use, distribution, and reproduction in any medium, provided the original work is properly credited. 
Credit risk discloses the likelihood of target agents reneging on promises (in terms of contracts). Particularly, when investing in government debt or loans, country (or government) credit should be considered a primary risk factor, namely, country risk represents the debt paying capability of the government. Similarly, when trading in commodity markets and investing in financial markets, the ability of the target corporations or individuals to meet debt obligations should be carefully estimated by credit scoring or rating using information about history records, current economic state, and other attributes (Huang et al. 2004; Huang et al. 2006). For example, commercial banks make financial loan decisions and issue credit cards to customers dependent on corporate (or individual) credit ratings or credit scores. Moreover, the rapid development of online markets has facilitated economic activity through networks, and the new concept of network credit has aroused increasingly wide interest concerning corresponding participant credit risk evaluation based on vast amounts of online historic data (Xu and Zhang 2009).

The existing studies on country (or government), corporate, individual, and network credit are based on three main perspectives: theoretical foundation, scoring methods, and regulatory mechanisms. Credit theory, as the theoretical foundation of social credit, explores the economic explanation of social credit in conjunction with creation and evolution mechanisms. The research approaches show that existing studies can be categorized according to two main schools of thought - traditional and emerging credit theories. While the former investigates credit theory based on various economics theories, e.g., institutional economics, information economics, and game theory (Stiglitz and Weiss 1981; Jarrow and Xu 2010; Brown and Zehnder 2010), the emerging studies utilize various current experimental techniques for complex systems, such as multi-agent-based models, system dynamics, and other simulation methods (Jankowitsch et al. 2007; Barnaud et al. 2008).

Credit scoring to quantify the credit risk of various agents has been and remains the major concern in the field of social credit. To enhance evaluation accuracy, various prediction techniques have been formulated and introduced, which can be categorized into four groups: expert system approaches (Altman 1968; Somerville and Taffler 1995), traditional econometric models (Doumpos et al. 2001; Pasiouras and Tanna 2010; Yim and Mitchell 2005), artificial intelligence (AI) techniques (Blanco et al. 2013; Yu and Yao 2013; Han et al. 2013), and their hybrids (Yim and Mitchell 2005; Lee et al. 2002; Chen and Huang 2003; Lee and Chen 2005; Hsieh 2005). Moreover, the explanatory variables (or evaluation indexes) play an important role in credit rating prediction and vary across different target agents. For example, country risk includes a country's economic, financial, social, cultural, geographic, and political fields and extends to its relationship with other countries ( $\mathrm{Li}$ et al. 2012a; Balkan 1992; Block and Vaaler 2004; Beirne and Fratzscher 2013). Evaluation indexes for corporate credit can be divided into financial and nonfinancial indicators (Duffee and Zhou 2001; Min and Lee 2008). And individual credit considers the various inner and external factors of the target customer (Avery et al. 2004; Bellotti and Crook 2009; Chuang and Lin 2009).

Regulatory mechanisms supervise the credit risk of various agents to avoid credit fraud. According to existing studies, establishing credit databases might be one of the most pressing tasks, and consistent data standards have been thoroughly discussed as a vital requirement (Zhang and Smyth 2009). Moreover, numerous existing studies 
focus on credit information sharing and the associated rules and regulations (Hunt 2005).

With respect to the literature reviews on social credit, numerous existing studies have focused on credit scoring techniques (Yim and Mitchell 2005; Blanco et al. 2013; Chen et al. 2009; Tseng and $\mathrm{Hu} 2010$ ) while ignoring other important aspects of credit theory, evaluation indices, and regulatory mechanisms. Moreover, the related studies have focused mainly on the credit risk of one specific economic agent such as country credit (Doumpos et al. 2001; Fioramanti 2006; Alp et al. 2011), corporate credit (Blanco et al. 2013; Zhou et al. 2005; Tang and Chi 2005) or individual credit (Baesens et al. 2003a; Desai et al. 1996; West 2000) while neglecting other agents. In this context, this study fills this literature gap by providing a comprehensive review of literature on social credit from the perspectives of theoretical foundation, scoring methods, and regulatory mechanisms, in which various economic agents in the social credit system (i.e., countries (or governments), companies, individuals, and netizens) are considered.

This paper provides a comprehensive review of the social credit literature. The remainder of the paper is structured as follows. Section Analytical framework for the literature review presents the analytical framework of social credit. A historical review of the theoretical (or model) development for all economic agents is presented in Sections Theoretical foundation, Scoring methods, and Regulatory mechanisms from the perspectives of theoretical foundation, scoring methods, and regulatory mechanisms, respectively. Finally, Section Summary and conclusions concludes the paper.

\section{Analytical framework for the literature review}

Although social credit lacks a uniform definition, it is widely considered a useful criterion in assessing the risk of a target economic agent reneging on promises. A lower credit score (or rating) indicates a greater risk of credit fraud. Therefore, various agents in economic systems should be assessed within the social credit framework including countries (or governments), corporations, and individuals. Social credit, therefore, encompasses country credit, corporate credit, and individual credit for different agents. Moreover, the development of online markets has facilitated network economic activities by agents, and the new concept of network credit can be incorporated into the social credit framework. Fig. 1 illustrates the social credit system.

Existing research for country (or government), corporate, individual, and network credit has focused on three aspects: the theoretical foundation, scoring methods, and regulatory mechanisms. Particularly, credit theory investigates the economic explanation for the social credit of various agents in conjunction with the creation and evolution mechanisms. Credit scoring quantifies the credit risk of various agents using various evaluation techniques and indexes, and regulatory mechanisms supervise the credit risk of various agents to avoid further credit fraud. Fig. 2 shows the analytical framework design for the literature review.

Using the analytical framework as shown in Fig. 2, Sections Theoretical foundation to Regulatory mechanisms present a historical review of the theoretical (or model) development of the economic agents, from the perspectives of theoretical foundation, scoring methods, and regulatory mechanisms. Additionally, important works and future research directions are outlined. 




\section{Theoretical foundation}

Social theory investigates the economic explanations, creation mechanisms, and evolution mechanisms for social credit encompassing country, corporate, and individual credit for different target agents.

Social theories for social credit can be classified into traditional and emerging theories that use different research techniques. Traditional theory incorporates various longstanding economic theories into the social credit framework to explore the economic explanations (or functions), creation, and evolution of credit. Some important works include Marx's credit theory (Marx and Engels 1867), Adam Smith's credit media theory (Smith 2005), Magruder's credit creation theory (Magruder 1923), Keynesian's credit expansion theory (Allen and Gale 2000), and Gurley's financial intermediary theory

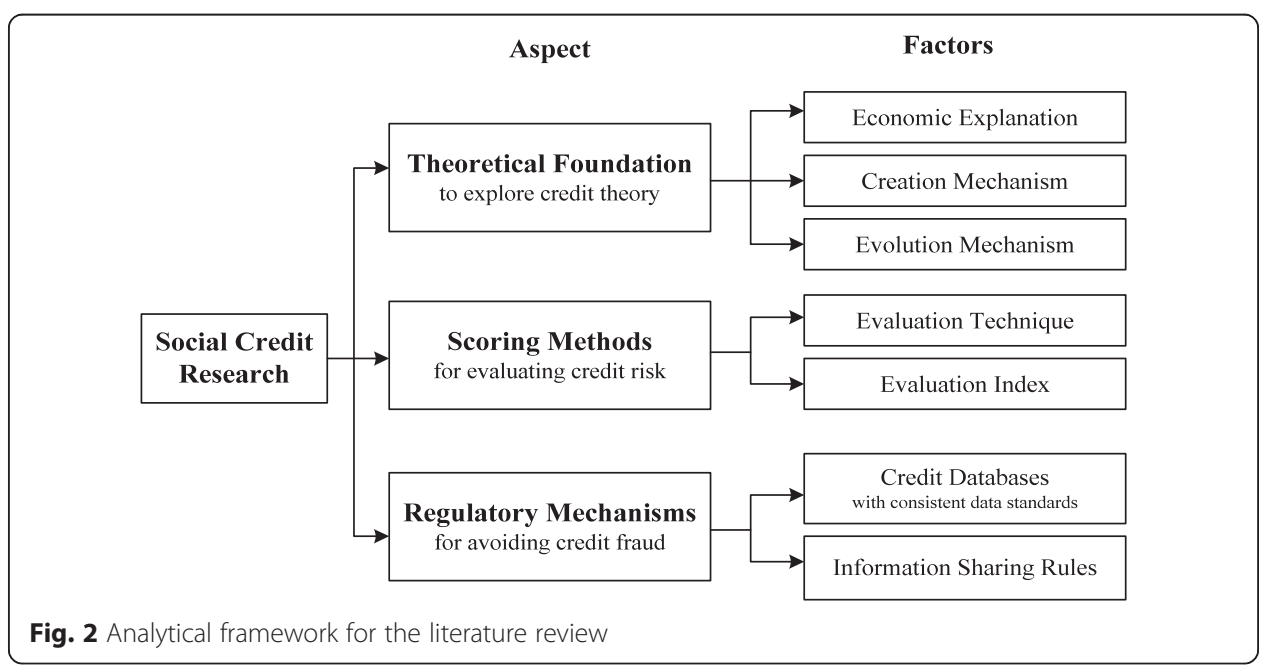


(Gurley and Shaw 1955; Gurley and Shaw 1956). Social credit theory is an indispensable component of financial intermediary theory, which can be included in traditional theory and modern theory (Chant 2003). Traditional financial intermediary theory includes credit medium theory and credit creation theory. While credit medium theory considers banks to be credit mediums, credit creation theory suggests that banks create credit. The modern financial intermediary theory focuses on credit risk management and argues that credit plays an important role in the economic system (Scholtens and van Wensveen 2003).

Studies on emerging credit theory have performed analyses based on information economics focusing on information mechanisms in the social credit system. For example, Stiglitz and Weiss 1981 and Jarrow and Xu 2010 argued that credit fraud is mainly caused by information asymmetry across different agents, and credit can be used as an important tool to avoid problems such as fraud. Additionally, various experimental simulation technologies, including multi-agent systems, system dynamics, and game theory have been applied to credit systems simulation to explore the creation and evolution mechanisms of credit. For example, Barnaud et al. 2008 employed multiagent system models with role-playing games (RPG) to simulate rural credit in a highland farming community of Northern Thailand. The authors found that an informal credit system between friends reduced credit fraud. Jankowitsch et al. 2007 developed a model of the economic value of credit rating systems based on statistical economic models. Brown and Zehnder 2010 employed game theory and provided a systematic analysis of information sharing mechanisms between lenders in the credit market with asymmetric information and competition.

With respect to future research direction, although experimental simulation technologies have been introduced and have become potentially effective tools for exploring social credit theory, the related studies remain insufficient compared with studies of traditional credit theory. Moreover, because only one specific agent, such as corporations or individuals, is considered in most of the existing research, the various economic agents under the social credit system (including countries (governments), corporations, individuals, and netizens) and their interactions require investigation to improve the existing research on social credit theory.

\section{Scoring methods}

Credit scoring is one of the most important components of social credit research. The associated studies have attempted to enhance evaluation accuracy of the credit risk of different agents. Regression techniques and evaluation indexes of scoring methods are critical factors. The following subsections provide a comprehensive literature review of each factor.

\section{Regression techniques}

Fig. 3 illustrates the various prediction techniques that have been introduced into social credit risk evaluation for regression analysis. These can be summarized as the expert system method, the econometric model, mathematical programming, AI tools, and their hybrid forms (i.e., hybrid system). 


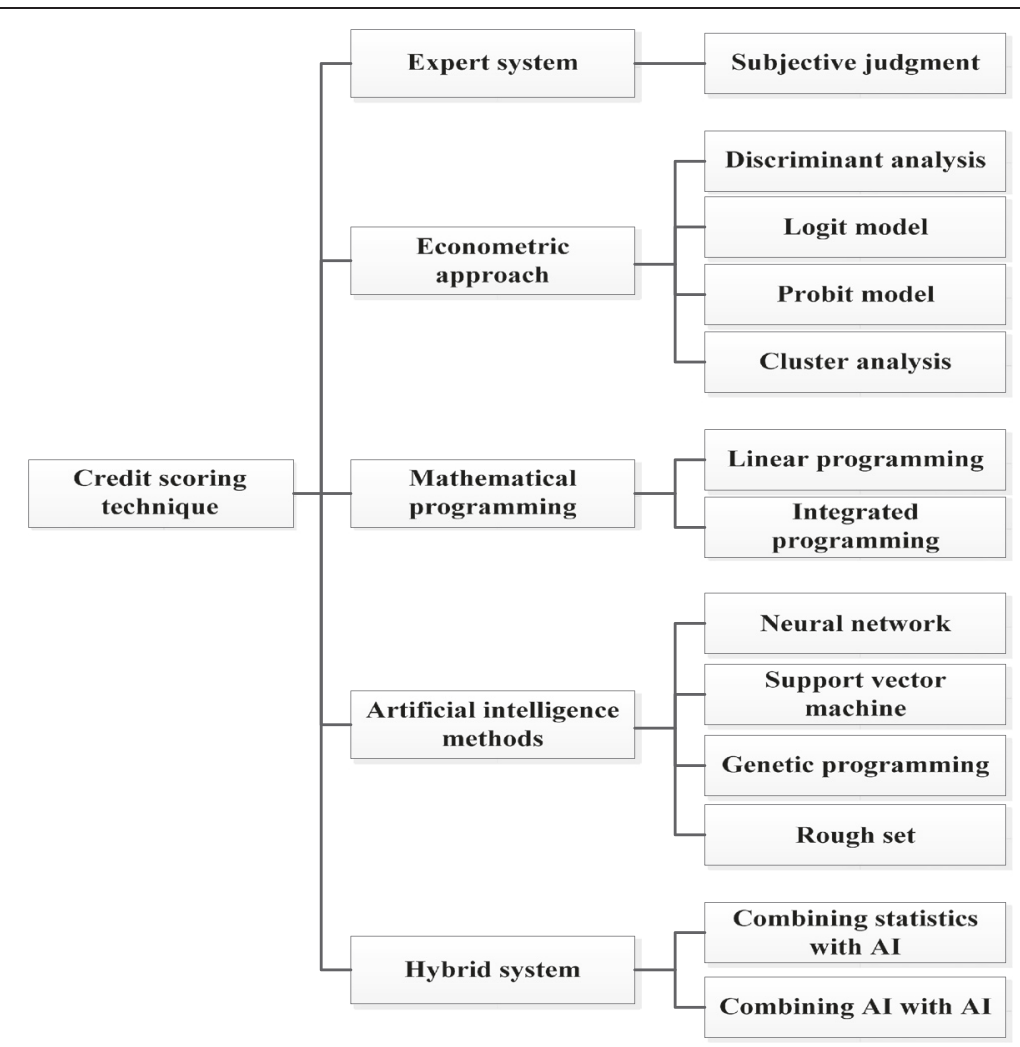

Fig. 3 Scoring techniques for social credit

\section{Expert systems}

Expert systems might be the most basic method employing subjective analysis (the socalled "expert" system) to assess credit risk. In expert systems, the evaluation index is the predominant factor determining the final score results. For example, the most famous evaluation index system for corporate credit is the 5C system (Altman 1968) for which the attributes of character, capacity, capital, collateral, and condition are subjectively judged (i.e., by expert judgment). Moreover, Somervile and Taffler 1995a compared banker judgment with other forecasting models (e.g., multi-variate statistical models) and considered Institutional Investor country credit ratings as other indicators of banker judgment.

However, the expert system approach is highly dependent on subjective judgment; therefore, the evaluation results for credit risk could be biased or discriminatory compared with other quantitative methods based on historic data.

\section{The econometric approach}

Econometric approaches are the most popular quantitative methods within the research fields of data analysis and prediction based on mathematics, statistics, and computer science. The methods capture the interactive relations between different variables (Pesaran 1987; Samuelson et al. 1954). According to the existing literature, the most popular approaches for credit scoring are discriminant analysis (DA), logit (or probit) models, cluster analysis, and $k$-nearest neighbor. Table 1 lists some significant works. 
Table 1 Typical works on credit scoring using econometric approaches

\begin{tabular}{lll}
\hline Agent & Reference & Technique \\
\hline Country & Frank and Cline (1971) & \\
& Grinols (1975) & \\
& Taffler and Abassi (1984) & \\
& Doumpos et al. (2001) & Logit \\
& Feder and Just (1977) & \\
& Rivoli and Brewer (1998) & Probit \\
& Fisk and Rimlinger (1979) & \\
& Balkan (1992) & DA \\
& Haan et al. (1997) & \\
& Altman (1968) & \\
Corporation & Beaver (1966) & Logit \\
& Zhou et al. (2005) & \\
& Tang and Chi (2005) & \\
& West (1985) & kNN \\
& West (1985) & \\
Chatterjee and Barcun (1970) & Henley and Hand (1997) \\
Bndividual & Baesens et al. 2003a, 2003b & \\
\hline
\end{tabular}

(1). Discriminant analysis

The DA method, one of the most basic methods, has been widely applied to credit risk evaluation since 1966 with a simple metric for use and interpretation.

Numerous studies on credit risk have used DA (Altman 1968; Beaver 1966; Frank and Cline 1971; Grinols 1975; Taffler and Abassi 1984; Doumpos et al. 2001). For example, Zhou et al. (Zhou et al. 2005) constructed a clients' credit model based on Bayes discriminant method and verified the effectiveness of this model in classifying clients according to different credit risk levels with low error-judgment. For country credit risk, Frank and Cline 1971 used linear and quadratic DA methods to determine the rescheduling abilities of countries. Grinols 1975 employed DA and showed the effectiveness of DA in country risk evaluation. Taffler and Abassi 1984 predicted developing countries' debt rescheduling with monetary policy and debt servicing indicators based on linear DA method and bankers' judgments. Doumpos et al. 2001 proposed the Multi-group Hierarchical Discrimination (MHDIS) multi-criteria decision aid method to classify 143 countries into four groups according to credit ratings. For corporate credit, Altman 1968 and Baever 1966 applied a uni-variate model and a multiple DA method to the classification and prediction of business creditworthiness. Another significant case is the DA-based ZETA model with seven variables proposed by Altman for credit risk. Altman and Narayanan 1997 further improved the model developing a five-variable model. Scott 1981 utilized the ZETA model to study bankruptcy prediction.

(2). The logit model

The logit model is a typical probabilistic statistical classification model. For country risk, Feder and Just 1977 determined the debt servicing capacities of countries and rescheduling probabilities with logit analysis. Rivoli and Brewer 
1998 employed a logistic regression model to evaluate country risk. For corporate credit risk, Tang and Chi 2005 predicted firm credit risk in the international trade context by applying receiver operating characteristic (ROC) curve analysis to compare model performances of traditional logit and fuzzy logic (FL) methods and supported FL as a more effective tool. West 1985 integrated factor analysis and logit estimation to propose a novel method for assessing bank condition, and the empirical results showed that the combination model was a potential method.

Additionally, some studies compared logit regression with other scoring techniques in credit ratings. For example, in the work by Saini and Bates 1978, the results showed that the logit model and the DA method performed similarly in country credit evaluation. Schmidt 1984 compared logit analysis with DA and cluster analysis and found that the logit model was superior to other methods of country credit scoring. Pasiouras and Tanna 2010 used the DA and logit analysis to estimate bank credit and showed that both estimation techniques achieved similar levels of prediction accuracy.

(3). The Probit model

The probit model is also an important classification method under the assumption that the cumulative probability distribution must be a standardized normal distribution. Compared with other approaches, relatively few studies on credit scoring used the probit model. Some significant works include Fisk and Rimlinger 1979, who studied long-term credit worthiness and rescheduling of developing countries based on a probit model. Balkan 1992 predicted country credit default using a probit model that included two important political risk variables (level of democracy and political instability). Haan et al. 1997 employed the probit model for government debt rescheduling.

(4). $k$-nearest neighbor method

The $k$-nearest neighbor ( $\mathrm{kNN})$ method is a standard nonparametric approach to classification considering only the $k$-most similar data instances. Chatterjee and Barcun 1970 first introduced the kNN method into credit scoring. Since this and similar studies, the kNN method has been applied extensively to credit evaluation. For example, Henley and Hand 1997 proposed a credit scoring system based on $k$-nearest-neighbor methods for individual credit risk and compared the method with other discrimination techniques. The results supported the effectiveness of the novel model. Baesens et al. 2003b employed $k$-nearest-neighbor method as benchmark for individual credit evaluation, and performed well.

\section{Mathematical programming methods}

Mangasarian 1965 first employed linear programming in classification prediction. For credit scoring, Vladimir et al. 2002 constructed a quadratic programming model for individual credit that included expert judgments. The numerical experiments showed that the evaluation model incorporating expert judgments can improve model performance. Kou et al. 2005 proposed a classification model using multicriteria linear programming to discover behavior patterns of credit card applicants. 


\section{Artificial intelligence methods}

Recently, various AI methods based on powerful computing learning abilities have become predominant techniques for credit scoring and classification. The most popular models for credit risk are artificial neural networks (ANN) and support vector machines (SVM). Table 2 shows some significant works.

\section{(1). Artificial neural networks}

Various ANNs have been used extensively in bankruptcy prediction since the 1990s (Odom and Sharda 1990; Tam and Kiang 1992) such as multi-layer perceptron (MLP), back-propagation (BP) algorithms (Tseng and Hu 2010; Wilson and Sharda 1994; Cooper 1999), fuzzy ANN (Basak et al. 1998), and radial basis function networks (RBFN) (Tseng and Hu 2010; Jang et al. 1997; Ranganath and Arun 1997). Additionally, existing studies fully proved that ANNs perform better than statistical models for credit risk prediction (Yim and Mitchell 2005; Wilson and Sharda 1994; Back et al. 1996).

For corporate credit, the first attempt using ANN to predict bankruptcy was performed by Odom and Sharda 1990, who compared three-layer feed-forward networks with multi-variate discriminant analysis. ANNs have been extensively used in bankruptcy or business failure prediction. For example, Tam and Kiang 1992 introduced ANNs in bankruptcy predictions. When compared with other methods (such as linear discriminant analysis, logistic regression, $k$-nearest neighbor, and the decision

Table 2 Typical works on credit scoring using Al techniques

\begin{tabular}{lll}
\hline Agent & Reference & Technique \\
\hline Country & Cooper (1999) & Neural networks \\
& Fioramanti (2006) & \\
& Alp et al. (2011) & Neural networks \\
& Odom and Sharda (1990) & \\
& Tam and Kiang's (1992) & \\
& Wilson and Sharda (1994) & \\
& Goonatilake and Treleaven (1995) & \\
& Tseng and Hu (2010) & \\
& Blanco et al. (2013) & SVM \\
& Huang et al. (2004) & \\
& Van Gestel et al. (2006) & Neural networks \\
& Desai et al. (1996) & \\
& Also, Davis et al. (1992) \\
& Piramuthu (1999) & \\
& West (2000) \\
& Desai et al. (1996) \\
Individual & Also, Davis et al. (1992) \\
& Piramuthu (1999) \\
& West (2000) \\
& Desai et al. (1997) \\
& Yobas et al. (2000) \\
& Ong et al. (2005) \\
& Huang et al. (2006) & \\
\hline
\end{tabular}


tree model), ANNs are more robust and accurate in bank status evaluation. For example, Wilson and Sharda 1994 found that neural networks were superior to DA and other statistical econometric methods. Gonatilake and Treleavan 1995 applied an MLP-based ANN as a credit scoring method, and the results indicated that the novel system can improve predictive accuracy. Tseng and Hu 2010 compared four different techniques which were the logit model, the quadratic interval logit model, the MLP, and the RBFN to forecast bankrupt firms in the UK and found that RBFN outperformed other models. Blanco et al. 2013 introduced ANNs as credit scoring models for 5,500 borrowers of a Peruvian microfinance institution, and the results revealed that neural network models outperform other classification techniques. For country risk, Cooper 1999 used the ANN model with a BP algorithm to investigate the rescheduling of international debt-service obligations. Fioramanti 2006 built an early warning system to predict a sovereign debt crisis based on ANNs, and the results indicated that ANNs were superior to some typical traditional methods. Alp et al. 2011 developed a continuous optimization model with the help of ANN techniques to predict country default risk, and the results showed that continuous optimization techniques can generate satisfactory results.

For individual credit, Desai et al. 1996 used a multi-layer perceptron neural network (i.e., a mixture of expert neural networks) for individual credit and found that neural network models outperform linear discriminant analysis and logistic regression models. Davis et al. 1992 studied the decision accuracy of decision trees and a multi-layer perceptron neural network for individual credit. The authors concluded that a comparable level of decision accuracy was obtained with the decision trees and the multi-layer perceptron neural network methods. Piramuthu 1999 employed a multi-layer perceptron neural network and a neural-fuzzy model to predict credit scoring for individual credit and indicated that neural networks obtain superior results. West 2000 used five neural network models: multi-layer perceptron, mixture-of-experts, radial basis function, learning vector quantization, and fuzzy adaptive resonance for individual credit. The author demonstrated that both the mixture-of-experts and radial basis function neural network models were superior to other models, and logistic regression was the most accurate of the traditional methods. Baesens et al. 2003a clarified the neural network decisions by explanatory rules that capture the learned knowledge embedded in the networks for individual credit, and concluded that neural network rule extraction and decision tables were powerful management tools to build advanced and userfriendly decision-support systems for credit-risk evaluation. Lee et al. 2006 argued that the classification and regression tree (CART) and multi-variate adaptive regression splines (MARS) for individual credit outperformed ANNs.

(2). Support vector machine

Support vector machines (SVM), another effective AI technique developed by Vapnik 2000 based on structural risk minimization, were recently introduced for credit scoring and have become a potentially effective tool. Some significant works include the following.

For individual credit, Schebesch and Stecking 2005 predicted applicants' credit scoring using an SVM database and concluded that SVMs performed slightly better than logistic regression. Li et al. 2006 evaluated consumer loan risk with SVMs on a small 
sample size and found that SVMs outperform multi-layer perceptron for individual credit. Huang et al. 2007 constructed hybrid SVM-based credit scoring model for individual credit and showed that the proposed hybrid GA-SVM strategy, combining genetic algorithms with SVM classifier, can simultaneously perform feature selection tasks and model parameter optimization. Bellotti and Crook 2009 compared SVM with traditional methods on a large credit card database for individual credit and found that SVM can be used as the basis of a feature selection method to discover the features most significant in determining default risk. Based on an intelligent integration framework including SVM, least squares SVM, and neural networks, Yu and Yao 2013; Yu et al. 2009a; Yu et al. 2009b; Yu et al. 2008; Yu et al. 2011; Yu et al. 2010 evaluated applicants' credit scores on different credit datasets and found improved classification accuracy. Li et al. 2012b studied an evolution strategy-based adaptive $L_{q}$ SVM model with Gauss kernel for individual credit risk analysis and demonstrated that the proposed approach performed better than other benchmark methods. Because SVMs suffers from the curse of dimension, Han et al. 2013 introduced an orthogonal SVM for individual credit scoring to address this problem and found that the proposed model reduced complexity, accelerated convergence, and achieved superior performance.

For corporate credit, Huang et al. 2004 applied SVM to predict corporate credit ratings and implied that SVM methods only slightly outperformed the back-propagation neural network (BNN). Van Gestel et al. 2006 used least squares SVM with a Bayesian kernel to derive classifiers for corporate bankruptcy and found that there was no significant difference between SVM, DA, and logistic regression in terms of the proportion of accurate test cases.

(3). Evolutionary techniques

With respect to credit scoring, the main goal of various models is to minimize evaluation errors; therefore, various evolutionary optimization techniques can be introduced into AI forecasting models to enhance evaluation accuracy. For example, Desai et al. 1997 utilized genetic algorithms (GA) in an ANN forecasting model for individual credit, and the results showed that the GA-based techniques performed somewhat better than the other methods. In addition to GA, genetic programming (GP) has also been applied. For example, Ong et al. 2005 used genetic programming (GP) for individual credit and concluded that GP is superior to benchmarks such as neural networks, decision trees, rough sets, and logistic regression. Huang et al. 2006 proposed two-stage genetic programming (2SGP) to manage individual credit scoring problems by incorporating the advantages of if-then rules and the discriminant function. The author found that 2SGP provides superior accuracy compared to other models.

\section{Hybrid systems}

Individual models have different limitations. Hybrid models that combine several individual model types can effectively exploit the merits of each model and address the drawbacks of others. Therefore, various hybrid models have been developed and introduced to obtain greater prediction accuracy in credit evaluation. Table 3 lists some significant works. 
Table 3 Typical works on credit scoring using hybrid models

\begin{tabular}{lll}
\hline Agent & Reference & Technique \\
\hline Country & Yim and Mitchell (2005) & Model based on statistical model and ANN \\
Corporation & Markham and Ragsdale (1995) & Model based on DA and ANN \\
& Jo and Han (1996) & Model based on ANN, statistical model and discriminant analysis \\
& Chuang and Lin (2009) & Model based on ANN and CBR-based technique \\
Individual & Lee et al. (2002) & Model based on ANN and DA \\
& Lee and Chen (2005) & Model based on ANN and MARS \\
& Hsieh (2005) & Model based on clustering analysis and ANNs \\
& Chen and Huang (2003) & Model based on ANN and GA \\
Chen et al. (2009) & Model based on SVM and three strategies \\
\hline
\end{tabular}

For country credit, Yim and Mitchell 2005 proposed a hybrid neural network combining statistical models with a neural network to predict country credit ratings and indicated that hybrid models outperformed all other models such as logit, probit, DA, and cluster techniques.

For corporate credit, Markham and Ragsdale 1995 combined output estimated by DA with an artificial network for corporate credit and stated that the hybrid model outperformed the statistical approaches in terms of classification. Jo and Han 1996 integrated the statistical model, discriminant analysis and two artificial intelligence models including neural network and case-based forecasting to evaluate corporate credit risk. The conclusion suggested that the integration approach produced higher prediction accuracy than individual models. Lee et al. 1996 developed hybrid neural network models that combined statistical techniques (i.e., multi-variate discriminant analysis (MDA) and the ID3 method with neural networks, or combined two different neural networks to predict corporate bankruptcy, and suggested that hybrid neural network models were potentially effective models for bankruptcy prediction.

For individual credit, Lee et al. 2002 proposed a credit scoring model integrating a BNN with a traditional DA approach for individual credit and implied that the proposed hybrid approach converged much faster than the conventional neural networks model and outperformed traditional DA and logistic regression methods. Lee and Chen 2005 proposed a two-stage hybrid credit scoring model employing ANN and multi-variate adaptive regression splines (MARS) for individual credit. The authors revealed that the hybrid credit scoring model outperformed DA, logistic regression, single ANNs and single MARS. Hsieh 2005 presented a hybrid approach combining clustering analysis with neural networks for individual credit and demonstrated that the hybrid approach was a potential tool for the evaluation of applicants' credit scores.

Recently, several studies have focused on decreasing type I and II errors in credit classification problems; that is, reassigning the rejected good credit applicants to the conditionally accepted class. For example, Chen and Huang 2003 proposed a hybrid methodology applying neural networks and genetic algorithms for individual credit and stated that the proposed hybrid model was a potentially effective tool for the prediction of credit scores and reassigning rejected instances. Chuang and Lin 2009 presented a reassigning credit scoring model (RCSM) integrating ANN and case-based 
reasoning (CBR)-based classification technique for individual credit and implied that the proposed hybrid model was more accurate than other commonly used credit scoring methods and also contributed to a reduction in type I errors in the scoring system. Chen et al. 2009 proposed a hybrid SVM technique based on three strategies: (1) using CART to select input features, (2) using MARS to select input features, and (3) using grid search to optimize model parameters for individual credit. The authors demonstrated that the hybrid SVM technique had the best classification rate and the lowest rate of type II errors compared with CART, MARS, and SVM.

\section{Future research directions}

Existing studies note other interesting points concerning improvements in credit scoring methods. First, the data preparation process, such as data collection, variable selection, and data cleaning for credit scoring prediction can help reduce noise levels and further enhance the evaluation accuracy of credit risk. However, most studies neglected to address this important process. Second, because hybrid systems have recently been introduced to social credit scoring and have demonstrated their superiority, even more powerful hybrid models can be formulated by combining various formidable AI tools. Third, existing credit scoring studies mainly focused on country, corporate, and individual credit while neglecting network credit. Therefore, evaluating variations of country, corporate, and individual credit in the network context should be considered as important future research directions.

\section{Indicator systems}

An indicator system (covering a set of evaluation indexes) is another significant component of the credit scoring model that directly determines evaluation results. Therefore, indicator systems should be designed to capture target agent features.

For country credit, the existing indicator system mainly encompasses a country's economic, financial, social, cultural, geographic, and political fields including its relationship with other countries ( $\mathrm{Li}$ et al. 2012a; Balkan 1992; Block and Vaaler 2004; Beirne and Fratzscher 2013). For example, Balkan Balkan 1992 proposed a model with two political risk variables (level of democracy and political instability) and some economic variables and showed that the novel model including the political variables generated superior results than the model limited to economic variables. Block and Vaaler 2004 argued that government stability is a significant index with a positive effect on government credit ratings. Yim and Mitchell 2005 classified the evaluation indexes for country risk into five categories: economics, balance of payments, external debt, government, and political risk. Beirne and Fratzscher 2013 found that government credit was sensitive to social stability and changes in financial markets.

For corporate credit, both macro-economic variables and micro-points representing a firm's state should be considered. Duffee and Zhou 2001 compared the effects of firm attributes and external factors on credit rating predictions. Min and Lee 2008 studied business bankruptcy models based on six variables: financial expenses to sales (FE), the current liabilities ratio $(\mathrm{CL})$, total borrowings and bonds payable to total assets (TB), the capital adequacy ratio (CA), the current ratio (CR), and the interest coverage ratio (IC).

For individual credit, Lee et al. 2002 introduced nine predictor variables: gender, age, marriage status, education, occupation, career level, annual income, residential status, 
and credit limit. Avery et al. 2004 found that the local economic situation and specific emergence had substantial influence on prediction accuracy for individual credit. Bellotti and Crook 2009 evaluated individual credit risk for credit card applicants based on 11 features: home ownership, time with bank, required insurance, the number of settled non-mail order credit account information sharing (CAIS) accounts, total outstanding balance excluding mortgages on all active CAIS accounts, total number of credit searches in the last six months, worst account status, age, product (type of credit card), time since the most delinquent account, and the UK Mosaic code. Chuang and Lin 2009 introduced 20 independent variables such as the credit card applicant's age, credit amount, credit history, employment, and housing.

With respect to future research, existing studies on indicator systems design mostly focused on countries (or government), corporations, and individuals as economic agents while neglecting online market credit. Therefore, selecting appropriate indicators for network credit evaluation is imperative for future research.

\section{Regulatory mechanisms}

Regulatory mechanisms supervise the credit risk of various agents to avoid further credit fraud. According to existing literature, establishing and sharing credit databases is one of the most pressing tasks currently under discussion (Zhang and Smyth 2009). For example, Miller 2000 investigated public and private worldwide credit data and concluded that public credit registries were not a substitute for private sector registries but a complement. Hunt 2005 reviewed the history of the individual credit reporting industry evolution and particularly emphasized the need for credit information sharing in the credit report industry by establishing credit standard systems and relevant rules. Smith et al. 2013 investigated credit reports from the three major US credit bureaus and suggested that credit bureau data were accurate, but individual consumers should ensure that potential errors do not occur in their records. Moreover, Zhang and Smyth 2009 analyzed the emerging credit reporting system in China and argued that substantial progress should be made through public and private credit-reporting services cooperation.

With respect to future research, progress can be achieved in the regulatory mechanisms for the social credit field. First, important credit data and reports from different agents including governments, corporations, and individuals should be used in the construction of credit databases. Second, existing studies on regulatory mechanisms have mostly used qualitative analysis; therefore, some quantitative experimental models, such as multi-agent-based systems and system dynamics, should be employed to explore the optimal regulatory mechanisms for social credit rules or designs. Third, the associated regulations concerning data protection and access to personal information deserve further investigations. Fourth, regulating network credit system has become an imperative task since the rapid development of online markets to guarantee a legitimate network environment and prevent network credit default.

\section{Summary and conclusions}

This paper provides a comprehensive review of the social credit literature from the perspectives of theoretical foundation, scoring methods, and regulatory mechanisms. The various economic agents' country (or government) credit, corporate credit, 
individual credit, and their variations in online markets (i.e., network credit) are considered. For each aspect, the study presents a historical review of the theoretical (or model) development for all economic agents together with important works and future research directions.

\section{(1). Credit theory}

Social theory investigates economic explanation, creation mechanisms, and evolution mechanisms for social credit encompassing country, corporate, and individual credit for different target agents.

Social theories on social credit can be classified into the traditional and emerging theories that use different research techniques. Traditional theory incorporates various traditional economic theories into the social credit framework to explore the economic explanation (or function), creation, and evolution of credit. Emerging credit theory performs analyses based on information economics and focuses on the information mechanisms in social credit systems.

(2). Credit scoring

Credit scoring might be the most important component of the social credit research field, and the most related studies attempt to enhance the evaluation accuracy of the credit risk of different agents. Regression techniques and evaluation indexes of scoring methods are critical factors.

With respect to regression, various prediction techniques have been introduced into social credit risk evaluation and can be categorized as expert systems, econometric models, mathematical programming, AI tools, and their hybrid forms. The results suggest that various hybrid approaches have been developed and have become an increasingly potential tool in evaluating credit scores.

Indicator systems (covering a set of evaluation indexes) are another important component of the credit scoring model that directly determines evaluation results. Therefore, indicator systems should be carefully designed to capture the features of target agents.

(3). Regulatory mechanisms

Regulatory mechanisms supervise the credit risk of various agents to avoid further credit fraud. Establishing and sharing a general credit database might be one of the most pressing tasks for which consistent data standards are currently being discussed.

(4). Future research directions

The existing studies on social credit can be improved. For social theory, the studies based on experimental simulation technologies are insufficient compared to the studies based on traditional credit theory. Additionally, a comprehensive exploration of the various economic agents and their interactions is another interesting research direction. With respect to credit scoring, additional powerful hybrid models should be formulated by combining various AI tools. For regulatory mechanisms, quantitative experimental models should be applied to explore the optimal regulatory mechanism rules or designs. The regulations concerning data protection and access to personal information deserve deep investigations. Regulating network credit systems has become an imperative task necessary to guarantee a legitimate network environment without credit fraud. 


\section{Competing interests}

The authors declare that they have no competing interests.

\section{Authors' contributions}

$L Y$ gave the main idea of the review paper and wrote the future direction of the paper. $X L$ collected some references and wrote the main body for the paper. LT wrote the main body of the paper and polished the full paper. ZZ gave some improvement suggestions and wrote the first section of the paper. GK discussed the main idea of the paper and wrote several intelligent algorithms for social credit. All authors read and approved the final manuscript.

\section{Acknowledgements}

This work is supported by grants from the National Science Fund for Distinguished Young Scholars (NSFC No. 71025005), the National Natural Science Foundation of China (NSFC No. 71433001 and NSFC No. 71301006), the National Program for Support of Top-Notch Young Professionals and the Fundamental Research Funds for the Central Universities in BUCT.

\section{Author details}

${ }^{1}$ School of Economics and Management, Beijing University of Chemical Technology, Beijing 100029, China. ${ }^{2}$ School of Business Administration, Southwestern University of Finance and Economics, Chengdu 611130, China.

Received: 9 May 2015 Accepted: 12 May 2015

Published online: 09 June 2015

\section{References}

Allen F, Gale D (2000) Bubbles and crises. Econ J 110(460):236-255

Alp ÖS, Büyükbebeci E, İşcanog A, Özkurt FY, Taylan P, Weber GW (2011) CMARS and GAM \& CQP_modern optimization methods applied to international credit default prediction. J Comput Appl Math 235(16):4639-4651

Altman El (1968) Financial ratios, discriminant analysis and the prediction of corporate bankruptcy. J Financ 23(4):589-609

Altman El, Narayanan P (1997) An international survey of business failure classification models. Financ Markets Inst Instrum 6(2):1-57

Avery RB, Calem PS, Canner GB (2004) Credit report accuracy and access to credit. Fed Res Bull 90:297

Back B, Laitinen T, Sere K (1996) Neural networks and genetic algorithms for bankruptcy predictions. Exp Syst Appl 11(4):407-413

Baesens B, Setiono R, Mues C, Vanthienen J (2003a) Using neural network rule extraction and decision tables for credit-risk evaluation. Manag Sci 49(3):312-329

Baesens B, Van Gestel T, Viaene S, Stepanova M, Suykens J, Vanthienen J (2003b) Benchmarking state-of-the-art classification algorithms for credit scoring. J Oper Res Soc 54(6):627-635

Balkan EM (1992) Political instability, country risk and probability of default. Appl Econ 24(9):999-1008

Barnaud C, Bousquet F, Trebuil G (2008) Multi-agent simulations to explore rules for rural credit in a highland farming community of Northern Thailand. Ecol Econ 66(4):615-627

Basak J, De RK, Pal SK (1998) Unsupervised feature selection using a neuro-fuzzy approach. Pattern Recogn Lett 19(11):997-1006

Beaver, WH (1966). Financial ratios as predictors of failure. J Account Res, 4, 71-111.

Beirne J, Fratzscher M (2013) The pricing of sovereign risk and contagion during the European sovereign debt crisis. $J$ Int Money Financ 34:60-82

Bellotti T, Crook J (2009) Support vector machines for credit scoring and discovery of significant features. Exp Syst Appl 36(2):3302-3308

Blanco A, Pino-MejíAs R, Lara J, Rayo S (2013) Credit scoring models for the microfinance industry using neural networks: evidence from Peru. Exp Syst Appl 40(1):356-364

Block SA, Vaaler PM (2004) The price of democracy: sovereign risk ratings, bond spreads and political business cycles in developing countries. J Int Money Financ 23(6):917-946

Brown M, Zehnder C (2010) The emergence of information sharing in credit markets. J Financ Intermed 19(2):255-278

Chant, J. (2003). Financial stability as a policy goal. Essays on financial stability, (95) [http://www.banqueducanada.ca/ wp-content/uploads/2010/01/tr95.pdf\#page=19]

Chatterjee S, Barcun S (1970) A nonparametric approach to credit screening. J Am Stat Assoc 65(329):150-154

Chen MC, Huang SH (2003) Credit scoring and rejected instances reassigning through evolutionary computation techniques. Exp Syst Appl 24(4):433-441

Chen W, Ma C, Ma L (2009) Mining the customer credit using hybrid support vector machine technique. Exp Syst Appl 36(4):7611-7616

Chuang CL, Lin RH (2009) Constructing a reassigning credit scoring model. Exp Syst Appl 36(2):1685-1694

Cooper JC (1999) Artificial neural networks versus multivariate statistics: an application from economics. J Appl Stat 26(8):909-921

Davis RH, Edelman DB, Gammerman AJ (1992) Machine-learning algorithms for credit-card applications. IMA J Manag Math 4(1):43-51

Desai VS, Crook JN, Overstreet GA (1996) A comparison of neural networks and linear scoring models in the credit union environment. Eur J Oper Res 95(1):24-37

Desai VS, Conway DG, Crook JN, Overstreet GAJ (1997) Credit-scoring models in the credit-union environment using neural networks and genetic algorithms. IMA J Manag Math 8(4):323-346

Doumpos M, Pentaraki K, Zopounidis C, Agorastos C (2001) Assessing country risk using a multi-group discrimination method: a comparative analysis. Manag Financ 27(8):16-34

Duffee GR, Zhou C (2001) Credit derivatives in banking: useful tools for managing risk? J Monet Econ 48(1):25-54 
Feder G, Just RE (1977) A study of debt servicing capacity applying logit analysis. J Dev Econ 4(1):25-38 Fioramanti M (2006) Predicting Sovereign Debt Crises Using Artificial Neural Networks: A Comparative Approach (No. 72). ISTAT-Italian National Institute of Statistics, Rome, ITALY

Fisk C, Rimlinger F (1979) Nonparametric estimates of LDC repayment prospects. J Financ 34(2):429-436

Frank CR, Cline WR (1971) Measurement of debt servicing capacity: an application of discriminant analysis. J Int Econ 1(3):327-344

Goonatilake, S, and Treleaven, PC (1995). Intelligent systems for finance and business. John Wiley \& Sons, Inc. Grinols, E (1975). International debt rescheduling and discrimination using financial variables. Earl Grinols. Gurley, JG, Shaw, ES (1955). Financial aspects of economic development. Am Econ Rev, 45(4):515-538.

Gurley JG, Shaw ES (1956) Financial Intermediaries and the saving-investment process. J Financ 11(2):257-276 Haan JD, Siermann CL, Lubek EV (1997) Political instability and country risk: new evidence. Appl Econ Lett 4(11):703-707

Han L, Han L, Zhao H (2013) Orthogonal support vector machine for credit scoring. Eng Appl Artif Intel 26(2):848-862

Henley WE, Hand D (1997) Construction of a K-nearest-neighbour credit-scoring system. IMA J Manag Math 8(4):305-321

Hsieh NC (2005) Hybrid mining approach in the design of credit scoring models. Exp Syst Appl 28(4):655-665

Huang Z, Chen H, Hsu CJ, Chen WH, Wu S (2004) Credit rating analysis with support vector machines and neural networks: a market comparative study. Decis Support Syst 37(4):543-558

Huang JJ, Tzeng GH, Ong CS (2006) Two-Stage Genetic Programming (2sgp) for the credit scoring model. Appl Math Comput 174(2):1039-1053

Huang CL, Chen MC, Wang CJ (2007) Credit scoring with a data mining approach based on support vector machines. Exp Syst Appl 33(4):847-856

Hunt RM (2005) A century of consumer credit reporting in America

Jang JSR, Sun CT, Mizutani E (1997) Neuro-fuzzy and soft computing-a computational approach to learning and machine intelligence [Book Review]. Autom Control IEEE Trans On 42(10):1482-1484

Jankowitsch R, Pichler S, Schwaiger WS (2007) Modelling the economic value of credit rating systems. J Bank Financ 31(1):181-198

Jarrow R, Xu L (2010) Credit rating accuracy and incentives. J Credit Risk 6(3):1-19

Jo H, Han I (1996) Integration of case-based forecasting, neural network, and discriminant analysis for bankruptcy prediction. Exp Syst Appl 11(4):415-422

Kou G, Peng Y, Shi Y, Wise M, Xu W (2005) Discovering credit cardholders' behavior by multiple criteria linear programming. Ann Oper Res 135(1):261-274

Lee TS, Chen IF (2005) A two-stage hybrid credit scoring model using artificial neural networks and multivariate adaptive regression splines. Exp Syst Appl 28(4):743-752

Lee KC, Han I, Kwon Y (1996) Hybrid neural network models for bankruptcy predictions. Decis Support Syst 18(1):63-72

Lee TS, Chiu CC, Lu CJ, Chen IF (2002) Credit scoring using the hybrid neural discriminant technique. Exp Syst Appl 23(3):245-254

Lee TS, Chiu CC, Chou YC, Lu CJ (2006) Mining the customer credit using classification and regression tree and multivariate adaptive regression splines. Comput Stat Data Anal 50(4):1113-1130

Li ST, Shiue W, Huang MH (2006) The evaluation of consumer loans using support vector machines. Exp Syst Appl 30(4):772-782

Li JP, Tang L, Sun XL, Yu L, He W, Yang YY (2012a) Country risk forecasting for major oil exporting countries: a decomposition hybrid approach. Comput Ind Eng 63(3):641-651

Li J, Li G, Sun D, Lee CF (2012b) Evolution strategy based adaptive L q penalty support vector machines with Gauss kernel for credit risk analysis. Appl Soft Comput 12(8):2675-2682

Longstaff FA, Mithal S, Neis E (2005) Corporate yield spreads: default risk or liquidity? New evidence from the credit default swap market. J Financ 60(5):2213-2253

Magruder, C. (1923). The Position of Shareholders in Business Trusts. Columbia Law Review, 23(5):423-443.

Mangasarian OL (1965) Linear and nonlinear separation of pat-terns by linear programming. Oper Res 13:444-452

Markham IS, Ragsdale CT (1995) Combining neural networks and statistical predictions to solve the classification problem in discriminant analysis*. Decis Sci 26(2):229-242

Marx, K, Engels, F (1867). Das Kapital: Kritik der politischen Ökonomie (Vol. 1, No. 1). Meissner.

Miller M (2000) Credit Reporting Systems Around the Globe: The State of The Art in Public and Private Credit Registries. In: World Bank. Presented at the Second Consumer Credit Reporting World Conference, held in San Francisco, California, October

Min JH, Lee YC (2008) A practical approach to credit scoring. Exp Syst Appl 35(4):1762-1770

Odom MD, Sharda R (1990) A Neural Network Model for Bankruptcy Prediction. In: Neural Networks, 1990., 1990 IJCNN International Joint Conference on., pp 163-168

Ong CS, Huang JJ, Tzeng GH (2005) Building credit scoring models using genetic programming. Exp Syst Appl 29(1):41-47

Pasiouras F, Tanna S (2010) The prediction of bank acquisition targets with discriminant and logit analyses: methodological issues and empirical evidence. Res Int Bus Financ 24(1):39-61

Pesaran MH (1987) The Limits to Rational Expectations. Blackwell, Oxford

Petersen MA, Rajan RG (2002) Does distance still matter? The information revolution in small business lending. J Financ 57(6):2533-2570

Piramuthu S (1999) Financial credit-risk evaluation with neural and neurofuzzy systems. Eur J Oper Res 112(2):310-321

Prati A, Schindler M, Valenzuela P (2012) Who benefits from capital account liberalization? Evidence from firm-level credit ratings data. J Int Money Financ 31(6):1649-1673

Ranganath S, Arun K (1997) Face recognition using transform features and neural networks. Pattern Recogn 30(10):1615-1622

Rivoli P, Brewer TL (1998) Political instability and country risk. Glob Financ J 8(2):309-321 
Saini, K, Bates, P (1978). Statistical techniques for determining debt-servicing capacity for developing countries: Analytical review of the literature and further empirical results. Federal Reserve Bank of New York.

Samuelson PA, Koopmans TC, Stone JRN (1954) Report of the Evaluative Committee for Econometrica

Schebesch KB, Stecking R (2005) Support vector machines for classifying and describing credit applicants: detecting typical and critical regions. J Oper Res Soc 56(9):1082-1088

Schmidt R (1984) Early warning of debt rescheduling. J Bank Financ 8(2):357-370

Scholtens B, van Wensveen D (2003) The Theory of Financial Intermediation. SUERF, Vienna

Scott J (1981) The probability of bankruptcy: a comparison of empirical predictions and theoretical models. J Bank Financ 5(3):317-344

Smith, A (2005). Wealth of nations. University of Chicago Bookstore, Chicago.

Smith LD, Staten M, Eyssell T, Karig M, Freeborn BA, Golden A (2013) Accuracy of information maintained by US Credit Bureaus: frequency of errors and effects on consumers' credit scores. J Consum Aff 47(3):588-601

Somerville RA, Taffler RJ (1995a) Banker judgement versus formal forecasting models: the case of country risk assessment. J Bank Financ 19(2):281-297

Stiglitz, JE, Weiss, A (1981). Credit rationing in markets with imperfect information. Am Econ Rev. 71(3):393-410

Taffler, RJ, Abassi, B (1984). Country risk: a model for predicting debt servicing problems in developing countries. Journal of the Royal Statistical Society. Series A (General), 147(4):541-568.

Tam KY, Kiang MY (1992) Managerial applications of neural networks: the case of bank failure predictions. Manag Sci 38(7):926-947

Tang TC, Chi LC (2005) Predicting multilateral trade credit risks: comparisons of Logit and Fuzzy Logic models using ROC curve analysis. Exp Syst Appl 28(3):547-556

Tseng FM, Hu YC (2010) Comparing four bankruptcy prediction models: Logit, quadratic interval logit, neural and fuzzy neural networks. Exp Syst Appl 37(3):1846-1853

Van Gestel T, Baesens B, Suykens JA, Van den Poel D, Baestaens DE, Willekens M (2006) Bayesian kernel based classification for financial distress detection. Eur J Oper Res 172(3):979-1003

Vapnik, V. (2000). The nature of statistical learning theory. Springer Science \& Business Media, Berlin.

Vladimir B, Hiroshi K, Stanislav U (2002) Credit cards scoring with quadratic utility functions. J Multicrit Decis Anal 11(4-5):197

West RC (1985) A factor-analytic approach to bank condition. J Bank Financ 9(2):253-266

West D (2000) Neural network credit scoring models. Comput Oper Res 27(11):1131-1152

Wilson RL, Sharda R (1994) Bankruptcy prediction using neural networks. Decis Support Syst 11(5):545-557

Xu Y, Zhang Y (2009) A online credit evaluation method based on AHP and SPA. Commun Nonlinear Sci Numer Simul 14(7):3031-3036

Yim J, Mitchell H (2005) Comparison of country risk models: hybrid neural networks, logit models, discriminant analysis and cluster techniques. Exp Syst Appl 28(1):137-148

Yobas MB, Crook JN, Ross P (2000) Credit scoring using neural and evolutionary techniques. IMA J Manag Math 11(2): 111-125.

Yu L, Yao X (2013) A total least squares proximal support vector classifier for credit risk evaluation. Soft Comput 17(4):643-650

Yu, L., Wang, S., Lai, K. K., \& Zhou, L. (2008). Biolnspired Credit Risk Analysis. Springer, Heidelberg.

Yu L, Wang S, Cao J (2009a) A modified least squares support vector machine classifier with application to credit risk analysis. Int J Inf Technol Decis Mak 8(04):697-710

Yu L, Wang S, Lai KK (2009b) An intelligent-agent-based fuzzy group decision making model for financial multicriteria decision support: the case of credit scoring. Eur J Oper Res 195(3):942-959

Yu L, Yue W, Wang S, Lai KK (2010) Support vector machine based multiagent ensemble learning for credit risk evaluation. Exp Syst Appl 37(2):1351-1360

Yu L, Yao X, Wang S, Lai KK (2011) Credit risk evaluation using a weighted least squares SVM classifier with design of experiment for parameter selection. Exp Syst Appl 38(12):15392-15399

Zhang G, Smyth R (2009) An emerging credit-reporting system in China. Chin Econ 42(5):40-57

Zhou H, Niu WJ, Wang Y (2005) Discriminant Analysis of Clients' Credit Management in Electricity Market. In: Transmission and Distribution Conference and Exhibition: Asia and Pacific, IEEE/PES., pp 1-6

\section{Submit your manuscript to a SpringerOpen ${ }^{\circ}$ journal and benefit from:}

- Convenient online submission

- Rigorous peer review

- Immediate publication on acceptance

- Open access: articles freely available online

- High visibility within the field

- Retaining the copyright to your article 